С. К. Малахаева

Байкальский государственный университет, г. Иркутск, Российская Федерация

М. Ю. Уварова

Иркутский государственный университет 2. Иркутск, Российская Федерация

Е. А. Кедярова

Иркутский государственный университет г. Иркутск, Российская Федерация

\title{
ИССЛЕДОВАНИЕ ЦЕННОСТНЫХ ОРИЕНТАЦИЙ РОССИЙСКИХ СТУДЕНТОВ, ОБУЧАЮЩИХСЯ В КИТАЕ
}

\begin{abstract}
АНнОтАЦИЯ. В статье представлен сравнительный анализ ценностных ориентаций российских студентов, обучающихся за рубежом, в частности в Китае, Ляонинском университете г. Шеньяна и обучающихся в Иркутском государственном университете. В исследовании установлено, что для студентов обеих групп (лингвистов и психологов) характерно наличие одинакового уровня выраженности ценностей, не затрагиваемых спецификой обучения и условиями проживания: высокое материальное положение, достижения, сохранение собственной индивидуальности. Представленные результаты позволяют заключить, что российские студенты, обучающиеся за рубежом, больше ориентированы на достижение успеха, самостоятельность и конформность. Тогда как студентов, обучающихся в России, характеризует стремление к социальному одобрению, к сдерживанию и предотвращению действий, которые могут причинить вред другим или не соответствуют социальным ожиданиям.

кЛЮчЕВЫЕ слОВА. Ценностные ориентации; студенты-лингвисты; студенты-психологи; потребность в автономии; независимости; в аффилиации.

ИНФОРМАЦИЯ О СТАТЬЕ. Дата поступления 19 октября 2017 г.; дата принятия к печати 19 декабря 2017 г.; дата онлайн-размещения 29 декабря 2017 г.
\end{abstract}

S. K. Malakhayeva Baikal State University, Irkutsk, Russian Federation

M. Yu. Uvarova

Irkutsk State University, Irkutsk, Russian Federation

Ye. A. Kedyarova

Irkutsk State University, Irkutsk, Russian Federation

\section{RESEARCH OF VALUE ORIENTATIONS OF RUSSIAN STUDENTS STUDYING IN CHINA}

ABSTRACT. The article presents a comparative analysis of value orientations of the Russian students studying abroad, in particular, in China, Liaoning University of Shenyang and students of Irkutsk State University. The study states that students of the both groups (linguists and psychologists) are characterized by presence of the same level of expression of the values that are not affected by the specifics of education and living conditions: high financial status, achievements, preservation of their own individuality. The results allow to conclude that the Russian students studying abroad are more focused on achieving success, independence and conformity. While the students studying in Russia are characterized by a tendency for social approval,

\section{Baikal Research Journal}


for containing and preventing actions that can harm others or do not meet social expectations.

KEYWORDS. Value orientations; students-linguists; students-psychologists; need for autonomy; independence; affiliation.

ARTICLE INFO. Received October 19, 2017; accepted December 19, 2017; available online December 29, 2017.

Неотъемлемой отличительной характеристикой современного российского общества является так называемая «интеллектуальная миграция» выезд за рубеж для получения профессионального образования. Вместе с тем, возможность учиться за рубежом, открывшаяся для молодежи России чревата для нашей страны потерей интеллектуального потенциала в случае невозвращения молодых людей после окончания учебы. Особую значимость в этой связи приобретает проблема выделения ценностных ориентаций у российских студентов, обучающихся за рубежом, так как данная категория молодежи с каждым годом становится все более многочисленной.

Большинство СМИ констатируют тот факт, что партнерские отношения в целом, а в образовательной среде, в частности, наиболее развиты у России с Китаем [1]. Поэтому нам представляется интересным изучение ценностных ориентаций российских студентов, выезжающих для обучения, именно в Китай.

В своём исследовании, мы исходили из предположения, что ценностные ориентации студентов, обучающихся за рубежом, отличаются самостоятельностью, повышенным уровнем достижений, ориентацией на построение карьеры и конформностью.

Теоретическим обоснованием нашей работы послужили исследования, посвященные изучению ценностных ориентаций современной молодежи, проведенные в разные годы В.Г. Алексеевой, Е.П. Белинской, Ю.М. Жукова, В.Г. Лукьянова, В.Б. Ольшанского, В.А. Ядова, М.С. Яницкого и др. Кроме того, для практического обоснования полученных результатов исследования мы опирались на концепцию М. Рокича, на основании которой все ценности делятся на терминальные и инструментальные и определяют содержание направленности личности, составляют ядро ее мотивации, жизненной установки, отражают отношение человека к себе, окружающему миру и другим людям и концепцию Ш. Шварца о мотивационной цели ценностных ориентаций и универсальности базовых человеческих ценностей.

Для проведения исследования нами были выбраны следующие методы: анкетирование; психодиагностический метод, который включал в себя 16-ти факторный опросник Р. Б. Кеттелла и «Ценностные ориентации» Ш. Шварца; метод математической статистики ( $\varphi$-критерий Фишера).

В число респондентов вошли 40 человек. Их них 20 человек, в возрасте от 19 до 21 года - студенты-лингвисты международного института Лингвистики и экономики (МИЭЛ), выезжающие в Ляонинский университет (Китай, Шеньян) для обучения и стажировки на 1,5 года и студенты-психологи в количестве 20 человек, в возрасте от 19 до 22 лет, обучающиеся на дневном отделении факультета психологии, с постоянным местом жительства в России. Все студенты являются студентами ФГБОУ «Иркутский государственный университет» .

Проведенный анализ литературы по исследуемой проблеме показал, что ценностные ориентации - это смысловые установки субъекта, осознанные им в процессе социализации, позволяющие личности сделать общественную духовную ценность своим достоянием, посредством уже принятых в обществе и зафиксированных в языке значений. Так, раскрывая сущность понятий ценностных ориен-

\section{Baikal Research Journal}

электронный научный журнал Байкальского государственного университета 
таций и ценностей, Ю.М. Жуков видит в них "детерминанты принятия решения» [2, с. 254-277], а В. Г. Алексеева рассматривает их как «основной канал превращения культурных ценностей в стимулы и мотивы практического поведения людей» [3, с. 63-70.].

Мы склоняемся к тому, что ценностные ориентации - сложный, но полностью упорядоченный комплекс принципов, возникающий в процессе оценивания как следствие взаимодействия трех различных элементов - когнитивного, аффективного и директивного - и определяющий поступки и мысли личности в той степени, в какой это связано с решением общечеловеческих проблем [4, с. 56]. Изменение ценностных ориентаций зависит от событий, происходящих в жизни субъекта, его перемещения в иную культурную среду, процессов взросления.

Студенчество является самой динамичной частью общества, которая чутко реагирует на малейшие изменения в его структуре [5]. По мнению Т.Э. Петровой, студенчество можно интерпретировать как «социальную группу переходного (по существу маргинального характера) с «отложенным» включением в социальные отношения» [6, с. 172-173]. Представляется более верным определение тех авторов, которые считают студенчество такой социальной группой, чьей основной характеристикой является «пограничность» (но не «маргинальность»). Ведь именно это фундаментальное свойство накладывает специфический отпечаток на формирование ценностных ориентаций. «Пограничность» делает студенчество самой динамичной частью общества, которая чутко реагирует на малейшие изменения в его структуре, его политические и экономические трансформации, быстро улавливает новые тенденции в культуре. Тот вроде бы малозначительный факт, что студенчество оперативнее, чем другие слои молодежной части общества, откликается на новые веяние в моде, литературе, кино, музыке, говорит об ее крайней восприимчивости к новому [4, с. 4]. Система ценностных ориентаций личности студента, в силу динамичности развития, отличает его от других возрастных категорий. Молодые люди, продолжающие обучение за рубежом, сталкиваются с необходимостью самостоятельного существования, что может быть причиной их быстрого взросления и соответственного изменения ценностей и мировоззрения в целом. Адаптация в новой социокультурной среде порождает стремление понять и усвоить ее нормы и ценности. Сравнение предшествующего жизненного опыта проведенного в российских реалиях с новыми переживаниями дает возможность четче сформулировать для себя жизненные ориентиры и продумать собственную стратегию дальнейших поисков. Особенно это характерно для молодых людей, которые в целом готовы меняться, готовы искать и работать над построением собственной субъектности.

В число ценностных ориентаций современных студентов вошли «руководящая работа», "признание, уважение», "успех» и «широкий круг общения», «широта взглядов» и «честность». А такие ценности, как «смелость» и «предприимчивость», характеризующие личностные качества, снижают, в процессе подготовки, свою ценность для студентов [7, с. 4].

Особо интересными для нашей работы представляются исследования основных факторов, влияющих на изменение ценностных ориентаций студенчества России и Китая, проведенные такими авторами как А.С. Панарин, В.В. Ильин (анализ структурных факторов), Л.П. Кукса, А.А. Булыгина, В.В. Козловский (анализ политико-идеологических факторов), Н. И. Лапина, А.А. Петрова (анализ экономических факторов) и духовных факторов - В.М. Фигуровская и В.Э Гельбрасо [8; 9, с. 74-75].

Изучению вопросов, связанных с численностью иностранцев, обучавшихся в вузах и других образовательных учреждениях КНР, посвящено множество как российских, так и китайских исследований [10].

\section{Baikal Research Journal}

электронный научный журнал Байкальского государственного университета 
Так, в докладе В.Я. Портякова (1999 г.) было отмечено, что с момента образования КНР как республики (1949 г.) численность студентов, приезжающих учиться в Китай, превысила 1,7 миллиона человек. Практически все прибывшие из-за рубежа студенты, стажеры, докторанты и т.п. занимаются по очной форме. Российские граждане обучаются в настоящее время почти в 100 высших учебных заведениях Китая, расположенных в 22 провинциях, 4-х городах центрального подчинения, а также в 3-х автономных районах. Наиболее популярными становятся вузы Северо-Восточных провинций КНР - Хэйлунцзян и Ляонин. При этом, наибольший прирост обучающихся из России пришелся на провинцию Ляонин (631 человек, в основном в г. Шеньян), а также на столицу КНР - Пекин (443 человека) [11].

Согласно статистическим данным, в 2016 году число российских студентов в КНР приблизилось к 18 тысячам, а число китайских учащихся в РФ превысило 30 тысяч. Вместе с тем насчитывается порядка 30 тысяч человек, которые участвуют в различных краткосрочных и более длительных программах по обмену. В связи с этим Китай и Россия постоянно принимают меры по поддержке и поощрению своих учащихся в поездках на учёбу в соседнюю страну. Советник-посланник Отдела по делам образования посольства КНР в РФ Чжао Гочэн отметил, что к концу 2016 года число китайских и российских студентов, обучающихся в рамках обмена между странами, превысило 70 тысяч. Более того, предполагается, что благодаря активному продвижению образовательных проектов со стороны правительств двух государств к 2020 году оно достигнет отметки в 100 тысяч учащихся [12].

Как отмечает в своей работе Портяков В.Я, при всем различии российской и китайской социальных систем существуют ряд связанных с традиционной, «базовой» ментальностью факторов, которые сближают ценностные схемы студенческой молодежи России и Китая, что позволяет делать вывод о том, что базовые ценности, с которыми наши студенты приехали в данную страну, остаются неизменными. $K$ духовно-ментальным следует отнести: патернализм; коллективизм: теократическо-христианский тип общежития в России, и родовой коллективизм конфуцианского толка в Китае. К географическому фактору относится: обширность территории; климатическое сходство и географическое соседство. $К$ экономическому фактору относится - традиционная аграрная экономика $[10 ; 13]$.

На формирование ценностных ориентаций российских студентов, обучающихся за рубежом, оказывают значимое влияние ряд факторов: коммуникационные барьеры, вырастающие из незнакомых и сложных лингвистических и паралингвистических особенностей; перемещение социокультурных принадлежностей, так как студент вынужден перемещаться между старыми и новыми культурными ценностями, идентификацией и т.п.; замена социального окружения - семьи, соседей и друзей одновременно, когда к студентам в новом социальном окружении относятся как к чужакам или даже непрошеным гостям; множественная отчетность - перед семьей, правительством или другим спонсором, преподавателями и иммиграционными службами.

Все вышеназванные трудности способствуют перераспределению иерархии ценностных ориентаций, где на первое место выходят самостоятельность и независимость, конкурентоспособность, творчество и познание для достижения более значимых целей, достижение успеха в жизни и уверенность в себе; образованность, эффективность и настойчивость, ценность свободы.

На следующем этапе нашего исследования мы выделили ценностные ориентации российских студентов, обучающихся за рубежом (в дальнейшем студенты-лингвисты).

Согласно результатам нашего исследования, 85 \% опрошенных студентов отмечают, что они не сталкивались за период учебы с какими-либо проявлениями

\section{Baikal Research Journal}

электронный научный журнал Байкальского государственного университета 
недружественных чувств, национализма и тем более не становились объектом физического насилия или нападений.

По результатам исследования при помощи 16-ти факторного опросника Кеттелла (табл. 1) мы можем сделать вывод о том, что у студентов-лингвистов преобладает высокий уровень настойчивости, подозрительности.

Это может быть объяснено тем, что проживание в другой стране требует быть всегда «на чеку», так как рядом нет родных и близких, с которыми можно поделиться своими переживаниями и эмоциями. Перемещение в инокультурную среду заставляет студентов пережить и сепарацию от родителей. Это может стать причиной ориентации на самостоятельность, ответственность за собственные поступки и выборы. Возможно, что самостоятельность в этом контексте будет сочетаться с ориентацией на автономию и независимость в построении собственных жизненных стратегий. Но может быть и фактором конформности к окружающей социальной среде с целью успешного включения в нее. При этом, студенты-лингвисты отличаются рассудительностью и осторожностью, имеют собственную точку зрения. Они внимательны к мелочам, которые другие люди могут не заметить. Они отличаются абстрактностью мышления, сообразительностью, проницательностью и эрудированностью. Мы можем предположить, что это связано с достаточно высокими требованиями и жёстким отбором студентов, отправляющихся на практику за границу.

Ранговые значения полученных средних показателей личностных характеристик студентов обеих групn

Таблица 1

\begin{tabular}{|c|c|c|c|c|c|c|c|c|c|c|c|c|c|c|c|c|}
\hline Студенты & 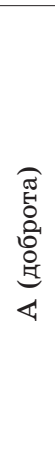 & 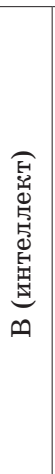 & 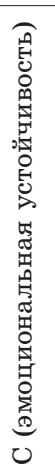 & 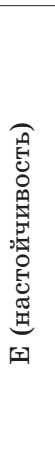 & 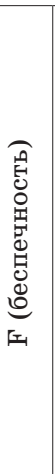 & 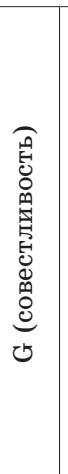 & 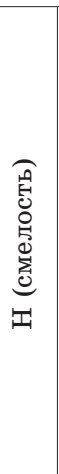 & 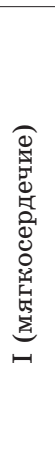 & 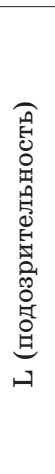 & 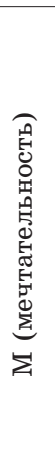 & 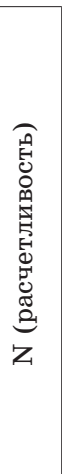 & 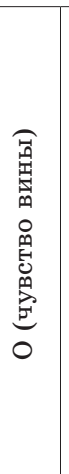 & 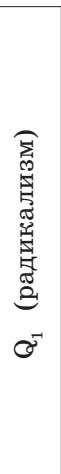 & 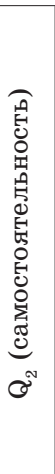 & 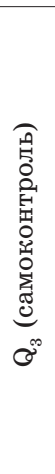 & 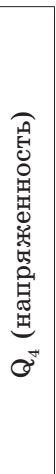 \\
\hline Лингвисты & 9 & 6 & 13 & 2 & 14 & 16 & 8 & 11 & 7 & 15 & 10 & 12 & 4 & 1 & 5 & 3 \\
\hline Психологи & 1 & 6 & 8 & 11 & 7 & 14 & 12 & 2 & 16 & 5 & 10 & 3 & 13 & 4 & 11 & 9 \\
\hline
\end{tabular}

Из табл. 1 видно, что по фактору $\mathrm{N}$ - расчетливость, об этой группе студентов можно судить как об откровенных, практичных людях, отличающихся прямотой.

Студенты-психологи же напротив отличаются мягкосердечностью и нежностью, стараются избегать конфликтных ситуаций или ситуаций, связанных с враждебностью, любят находиться в социальном окружении. Можно сказать, что для них значимой ценностной является «доброта». Они склонны к проявлению романтизма, часто смотрят на мир сквозь "розовые очки», обладают высокой артистичностью, что помогает им в общении с другими людьми. Развитая способность к сопереживанию и пониманию других людей, может говорить о специфике получаемой профессии.

Обращают на себя внимание показатели студентов-лингвистов, полученные по фактору G - совестливость, которые демонстрируют склонности к непосто-

\section{Baikal Research Journal}


янству, недостатку внутренних регуляторов, подверженность влиянию случая и обстоятельств, фиксации своего внимания на неудачах. Это может быть связано с особенностями возраста и условиями адаптации к другой культуре.

Студенты-лингвисты, в своем большинстве, хорошо ориентируются в житейских ситуациях, грамотно решают практические вопросы, отличаются уравновешенностью.

Полученные данные по 16-ти факторному опроснику Кеттелла позволяют нам подтвердить наличие тех ценностных ориентаций, которые были выявлены, благодаря проведению методики Шварца.

Прежде всего, отметим, что в результате исследования удалось выделить все десять исходных для авторского варианта методики факторов, отражающих основные мотивационные типы личности.

При анализе методики, направленной на измерение ценностей личности нами были получены следующие результаты:

Как видно из таблицы наиболее важными личностными ценностями для студентов - лингвистов являются: достижение, самостоятельность, конформность.

Для данного возрастного периода характерна высокая потребность в достижениях, т. е. стремление к достижению ощутимых и конкретных результатов в любом виде деятельности. Поэтому мы и получили высокие показатели по шкале достижения в обеих группах студентов. Эта потребность объясняется многими авторами и самим характером учебной деятельности студентов в целом [6, с. 66].

Что касается стремления к независимости и желании сохранить неповторимость, своеобразие собственной личности, своих взглядов и убеждений, то у студентов-лингвистов эти показатели несколько выше, чем у психологов. Это может быть связано с тем, что в условиях проживания и обучения в другой стране эти ценностные ориентации позволяют самосовершенствоваться, чтобы быть более конкурентоспособным. Кроме того у этой группы студентов отмечается стремление к социальной компетенции через личный успех, который является результатом собственной активности.

Исходя из полученных данных, можно предположить, что будущему специалисту-лингвисту свойственна потребность в автономии и независимости, также как и потребность в позитивном взаимодействии, в аффилиации.

Ранговые значения полученных средних показателей

Таблица 2 иенностных ориентаций двух групп студентов

\begin{tabular}{|l|r|r|r|r|r|r|r|r|r|r|}
\hline Студенты & $\begin{array}{c}\text { Кон- } \\
\text { форм- } \\
\text { ность }\end{array}$ & $\begin{array}{c}\text { Тради- } \\
\text { ции }\end{array}$ & $\begin{array}{c}\text { Добро- } \\
\text { та }\end{array}$ & $\begin{array}{c}\text { Уни- } \\
\text { верса- } \\
\text { лизм }\end{array}$ & $\begin{array}{c}\text { Самостоя- } \\
\text { тельность }\end{array}$ & $\begin{array}{c}\text { Стиму- } \\
\text { ляция }\end{array}$ & $\begin{array}{c}\text { Гедо- } \\
\text { низм }\end{array}$ & $\begin{array}{c}\text { Дости- } \\
\text { жения }\end{array}$ & $\begin{array}{c}\text { Власть } \\
\text { носопас- }\end{array}$ \\
\hline Лингвисты & 3 & 10 & 4 & 6 & 2 & 8 & 7 & 1 & 9 & 5 \\
\hline Психологи & 4 & 10 & 1 & 6 & 5 & 9 & 3 & 3 & 9 & 2 \\
\hline
\end{tabular}

Тогда как отвергаемыми ценностями становятся: традиции и власть. Это может говорить о том, что привязанность и консервативный стиль поведения не присущ данной группе испытуемых. Наоборот, стремление к новизне, поиск новых путей является для них более актуальным. Для успешности студента - лингвиста необходимыми качествами личности являются достижения, уважение и самостоятельность, что и видно из полученных результатов.

Одной из главных характерных черт ценностных систем респондентов лингвистов являются карьерные амбиции и стремления к достижениям. Мотивационный блок «власть», включающий в себя такие ценности как влиятельность,

\section{Baikal Research Journal}

электронный научный журнал Байкальского государственного университета 
власть, социальное признание, отвага и т.п., обладает не высоким значением по выборке, а непосредственно ценность социальной власти занимает предпоследнее (а именно девятое) место в иерархии ценностей респондентов. Скорее всего, на наш взгляд, это связано с тем, что понятие власти в сознании студентов, в целом, достаточно часто ассоциировано с политикой и государством.

Интересно, что студенты - лингвисты большое значение придают ценностям «достижения», среди которых наибольший вес имеют успех, профессиональная компетентность и интеллект. С нашей точки зрения, подобная особенность ценностных ориентаций респондентов является «оборотной стороной» желания стабилизации. Характерно, что ведущей стратегией достижения успеха признается постепенное, медленное его наращивание: сначала «получить образование», потом «найти хорошо оплачиваемую работу», потом «обустроиться в жизни», потом «завести семью», потом «получить второе образование». Это можно соотнести с «умеренностью, аккуратностью» и «конформностью» (одно из высоких значений по выборке), которые играют большую роль в стратегии достижения поставленных целей.

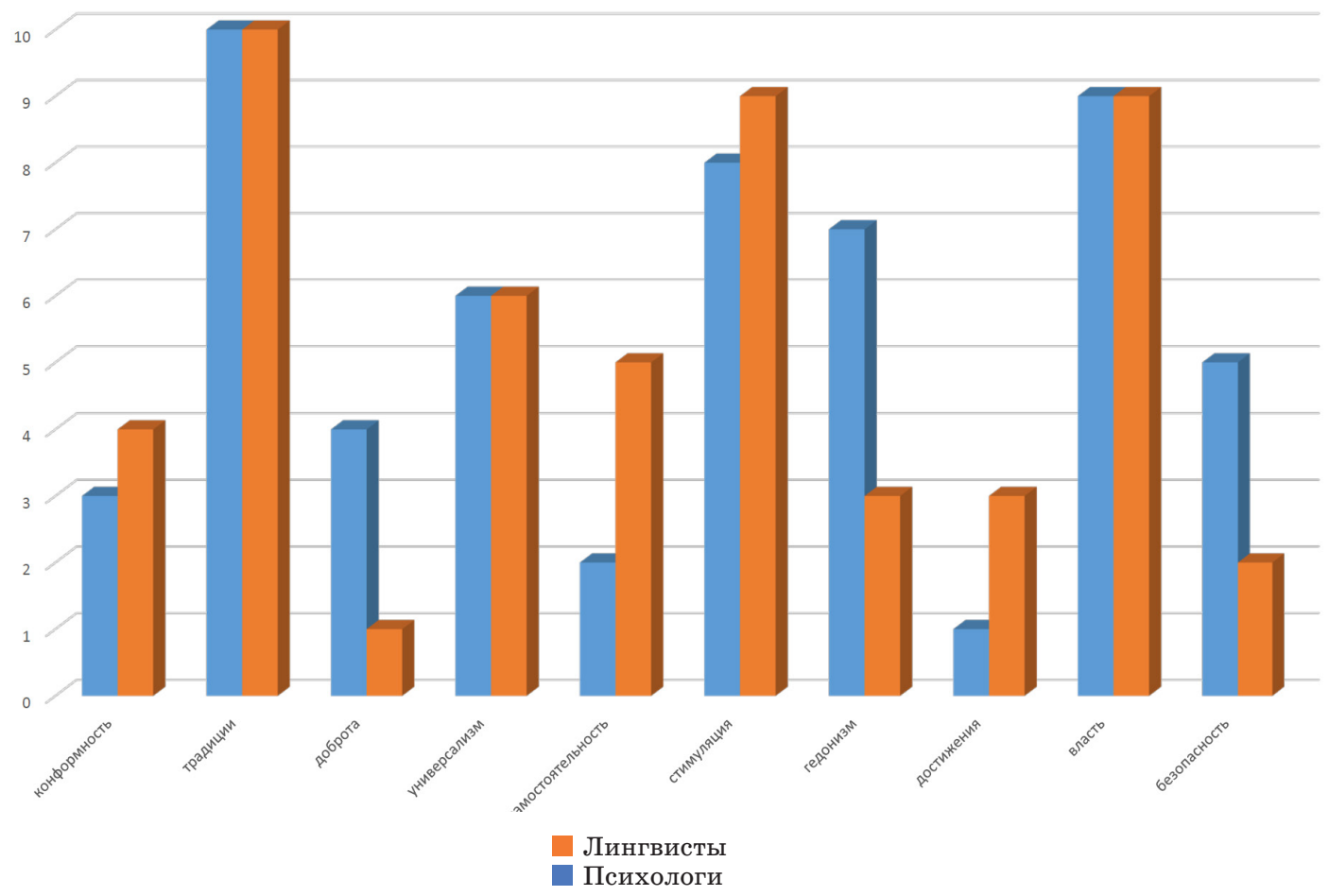

Рис. 1. Сравнение показателей рангов иенностных ориентаций среди двух групп студентов

Относительно высокие показатели по шкале «Доброта» говорят о стремлении к благополучию и безопасности в узком кругу родных и друзей, которое выступает для них одним из ведущих мотивов жизнедеятельности. Верная дружба, преданность, неприкосновенность своего внутреннего мира и особенно безопасность семьи оказываются ведущими ценностями. Интересен тот факт, что приверженность данным ценностям демонстрируется людьми, у которых пока нет семьи или которые еще только вступают в семейную жизнь, в большинстве своем еще не

\section{Baikal Research Journal}


успевшими обзавестись детьми и родители которых достаточно молоды, т.е. речь идет о ценностях завтрашнего дня, о долгосрочной перспективе. Можно предположить, что в этом случае на данные ориентации оказали влияние различные факторы. Так для лингвистов примером могли послужить культурные традиции жителей Китая, которые проповедуют ценности семьи. А вот высокие показатели у психологов можно соотнести с их будущей профессией.

По сравнению со студентами-психологами, студенты, обучающиеся за границей, имеют стремление к наслаждению и чувственному удовольствию (шкала гедонизм). Студенты же психологи стремятся к социальному одобрению, к сдерживанию и предотвращению действий и склонностей, которые могут причинить вред другим или не соответствуют социальным ожиданиям (данные по шкале конформизм).

Для более высокой достоверности полученных результатов мы провели их обработку по критерию Фишера. В соответствии с нашей гипотезой, мы выделили три шкалы ценностных ориентаций, стоящих на первых позициях иерархии ценностей студентов-лингвистов: достижения, самостоятельности и конформности в двух группах нашей выборки и подсчитали для каждой из этих шкал уровень достоверности результатов.

По шкале «достижения» коэффициент $\varphi=0,239$. Данный показатель не попадает в зону значимости результатов, следовательно, мы не можем говорить о статистической достоверности результатов, полученных по этой шкале. Шкала «конформность» с показателем $\varphi=0,339$ так же как и шкала «достижения» не попадает в зону значимости результатов. Исходя из статистических данных, мы не можем определенно сказать, что особенностью ценностных ориентаций студентов - лингвистов являются достижения или конформность. Хотя достижения и конформность как мотивационные типы присутствуют в системе ценностных ориентаций будущих специалистов-лингвистов, и даже у некоторых студентов являются доминирующими, но в то же время они не являются особенностями ценностных ориентаций данной группы испытуемых.

По шкале «самостоятельность» расчетный показатель $\varphi=2,820$, данный результат попадает в интервал значимости, что позволяет нам с уверенностью сказать и статистически доказать то, что самостоятельность, в данном случае является особенностью ценностных ориентаций студентов, обучающихся за рубежом в Ляонинском университете в г. Шеньян, в рамках стажировки.

Таким образом, благодаря проведенному нами исследованию, мы смогли доказать что одной из особенностей ценностных ориентаций российских студентов, выезжающих обучаться за границу является самостоятельность. Кроме того данным студентам свойственна потребность в автономии и независимости, также как и потребность в позитивном взаимодействии, в аффилиации.

\section{Список использованной литературы}

1. Белинская Е. П. Система ценностей личностей в перспективе толерантности [Электронный ресурс] / Е. П. Белинская // Век толерантности. - 2004. - № 5. - Режим доступа: http://www.tolerance.ru/VT-5-sistema.php?PrPage=VT.

2. Жуков Ю. М. Ценности как детерминанты принятия решения. Социальнопсихологический подход к проблеме / Ю. М. Жуков // Психологические проблемы социальной регуляции поведения. - М. : Наука, 1976. - С. 255-276.

3. Алексеева В. Г. Ценностные ориентации как фактор жизнедеятельности и развития личности / В. Г. Алексеева // Психологический журнал. - 1984. - Т. 5, № 5. - С. 63-70.

4. Карандашев В. Н. Методика Шварца для изучения ценностей личности: концепция и методическое руководство / В. Н. Карандашев. - СПб. : Речь, 2004. - 70 с.

\section{Baikal Research Journal}

электронный научный журнал Байкальского государственного университета 
5. Геранюшкина Г. П. Исследование готовности к предпринимательской деятельности у студентов экономического вуза / Г. П. Геранюшкина // Профориентация: вопросы теории и практики : материалы Всерос. науч.-практ. конф. / под ред. М. А. Сокольской. Хабаровск, 2015. - С. 34-41.

6. Петрова Т. Э. Социология студенчества в России. Этапы и закономерности становления / Т. Э. Петрова. - СПб. : Бельведер, 2000. -244 с.

7. Лисовский В. Т. Духовный мир и ценностные ориентации молодежи России : учеб. пособие / В. Т. Лисовский. - СПб., 2000. - 508 с.

8. Панарин А. С. Реванш истории: российская стратегическая инициатива в XXI веке / А. С. Панарин. - М. : Русский мир, 2005. - 432 с.

9. Фигуровская В. М. Духовные ценности на современном рынке / В. М. Фигуровская // Реформируемая Россия: социальные аспекты. - М., 1999. - С. 74-75.

10. Иванов И. Россия - Китай: к новому качеству отношений / И. Иванов // Российская газета. - 2016. - 18 мая.

11. Лукьянов В. Г. Изучение проблемы ценностей в современной философии / В. Г. Лукьянова // Методология гуманитарного знания в перспективе XXI века : материалы междунар. науч. конф. 18 мая 2001 г. Санкт-Петербург. - СПб., 2001. - Вып. 12. C. 221-224.

12. Жэньминьван. Китай и Россия постоянно углубляют сотрудничество в сфере образования / Жюньминьван // Правда. - 2017. - 8 сент. (№ 99).

13. Портяков В. Я. КНР в годы реформ: осмысление реформ / В. Я. Портяков // Проблемы и потенциал устойчивого развития Китая и России в XXI в. : тезисы докладов. М., 1999. - Ч. 1. - С. 9-15.

\section{References}

1. Belinskaya E. P. Value system of individuals in terms of tolerance. Vek tolerantnosti=Age of Tolerance, 2004, no. 5. Available at: http://www.tolerance.ru/VT-5-sistema.php?PrPage=VT. (In Russian).

2. Zhukov Yu. M. Values as determinants of decision-making. Socio-psychological approach to the problem. Psikhologicheskie problemy sotsial'noi regulyatsii povedeniya [Psychological problems of social regulation of behaviour]. Moscow, Nauka Publ., 1976, pp. 255-276. (In Russian).

3. Alekseeva V. G. Value orientations as a factor of life activity and personal development. Psikhologicheskii zhurnal = Psychological Journal, 1984, vol. 5, no. 5, pp. 63-70. (In Russian).

4. Karandashev V. N. Metodika Shvartsa dlya izucheniya tsennostei lichnosti: kontseptsiya $i$ metodicheskoe rukovodstvo [Schwartz's methods for studying personal values: concept and methodical guide]. Saint Petersburg, Rech', 2004. 70 p.

5. Geranyushkina G. P. Study of readiness for entrepreneurial activity among students of economic university. In Sokol'skaya M. A. (ed.). Proforientatsiya: voprosy teorii i praktiki. Materialy Vserossiiskoi nauchno-prakticheskoi konferentsii [Career orientation: theory and practice issues. Materials of All-Russian Scientific and Practical Conference]. Khabarovsk, 2015, pp. 34-41. (In Russian).

6. Petrova T. E. Sotsiologiya studenchestva $v$ Rossii. Etapy i za-konomernosti stanovleniya [Sociology of students in Russia. Stages and patterns of formation]. Saint Petersburg, Bel'veder Publ., 2000. 244 p.

7. Lisovskii V. T. Dukhovnyi mir i tsennostnye orientatsii molodezhi Rossii [Spiritual world and value orientations of Russian youth]. Saint Petersburg, 2000. 508 p.

8. Panarin A. S. Revansh istorii: rossiiskaya strategicheskaya initsiativa $v$ XXI veke [The history revenge: Russian strategic initiative in the 21st century]. Moscow, Russkii mir Publ., 2005. $432 \mathrm{p}$.

9. Figurovskaya V. M. Spiritual values on the modern market. Reformiruemaya Rossiya: sotsial'nye aspekty [Reformed Russia: Social Aspects]. Moscow, 1999, pp. 74-75. (In Russian).

10. Ivanov I. Russia-China: Towards the new quality of relations. Rossiiskaya gazeta, 2016, 18 may. (In Russian).

11. Luk'yanov V. G. Study of problem of values in modern philosophy. Metodologiya gumanitarnogo znaniya $v$ per-spektive XXI veka. Materialy mezhdunarodnoi nauchnoi

\section{Baikal Research Journal}


konferentsii. Sankt-Peterburg, 18 maya 2001 g. [Methodology of humanitarian knowledge in the perspective of the XXI century. Materials of International Scientific Conference. St. Petersburg, May 18, 2001] Saint Petersburg, 2001, vol. 12, pp. 221-224. (In Russian).

12. Zhen'min'van. China and Russia are constantly deepening cooperation in the field of education. Pravda, 2017, 8 september (№ 99). (In Russian).

13. Portyakov V. Ya. PRC in the years of reformation: understanding the reforms. Problemy $i$ potentsial ustoichivogo razvitiya Kitaya $i$ Rossii $v$ KhKhI $v$. Tezisy dokladov [Problems and potential for sustainable development of China and Russia in the $21^{\text {st }}$ century. Theses of reports]. Moscow, 1999, iss. 1, pp. 9-15. (In Russian).

\section{Информация об авторе}

Малахаева Светлана Карловна - кандидат философских наук, доцент, кафедра социальной и экономической психологии, социологии и социальной работы, Байкальский государственный университет, 664003, г. Иркутск, ул. Ленина, 11, e-mail: smalahaeva@ yandex.ru.

Уварова Маргарита Юрьевна - кандидат психологических наук, доцент, кафедра педагогической и возрастной психологии, Иркутский государственный университет, 664025, г. Иркутск, ул. Чкалова 2, 11, e-mail: uv-marg@mail.ru.

Кедярова Елена Александровна - кандидат психологических наук, доцент, кафедра педагогической и возрастной психологии, Иркутский государственный университет, 664025, г. Иркутск, ул. Чкалова 2, 11, e-mail: kedu_72@mail.ru.

\section{Authors}

Svetlana K. Malakhayeva - PhD in Philosophy, Associate Professor, Chair of Social and Economic Psychology, Sociology and Social Work, Baikal State University, 11 Lenin St., 664003, Irkutsk; e-mail: smalahaeva@yandex.ru.

Margarita Yu. Uvarova - PhD in Psychology, Associate Professor, Chair of Pedagogical and Age Psychology, Irkutsk State University, 2 Chkalov St., 664025, Irkutsk; e-mail: uvmarg@mail.ru.

Yelena A. Kedyarova - PhD in Psychology, Associate Professor, Chair of Pedagogical and Age Psychology, Irkutsk State University, 2 Chkalov St., 664025, Irkutsk; e-mail: kedu_72@ mail.ru.

\section{Для цитирования}

Малахаева С. К. Исследование ценностных ориентаций российских студентов, обучающихся в Китае / С. К. Малахаева, М. Ю. Уварова, Е. А. Кедярова // Baikal Research Journal. — 2017. - T. 8, № 4. - DOI : 10.17150/2411-6262.2017.8(4).8.

\section{For citation}

Malakhayeva S. K., Uvarova M. Yu., Kedyarova Ye. A. Research of value orientations of Russian students studying in China. Baikal Research Journal, 2017, vol. 8, no. 4. - DOI : 10.17150/2411-6262.2017.8(4).8. (In Russian).

\section{Baikal Research Journal}

